\title{
How Does the Death Conscious Culture of Iran Affect Experiences of Depression?
}

\author{
Moujan Mirdamadi ${ }^{1}$
}

Published online: 9 August 2018

(C) The Author(s) 2018

\begin{abstract}
This paper is divided into two parts. First I argue for the existence of a death-conscious culture in Iran, traceable in religious and literary texts, and manifested strongly in the discourse following the Iran-Iraq war. I then look at how this culture influences articulations and experiences of depression as felt by Iranian patients. Adopting a phenomenological perspective and drawing on empirical data, I show how death-consciousness, as a point of cultural divergence between the UK and Iran, can be used to account for some of the phenomenologically significant cultural variations in the experience of depression. These include attitudes towards suicide, the significance of feelings of hopelessness, and the existence of a sense of absurdity among Iranian patients.
\end{abstract}

Keywords Depression · Phenomenology · Iran · Suicide · Hopelessness · Absurdity

\section{Introduction}

Adopting a phenomenological perspective, this paper aims to show the effects of the death-conscious culture of Iran on articulations and experiences of depression. Recent research into the phenomenology of depression raises the question as to whether cultural variations give rise to culturally specific ways of experiencing the

Electronic supplementary material The online version of this article (https://doi.org/10.1007/s11013018-9597-4) contains supplementary material, which is available to authorized users.

Moujan Mirdamadi

m.mirdamadi@lancaster.ac.uk

1 Department of Politics, Philosophy, and Religion County South, Lancaster University, Lancaster LA1 4YL, UK 
illness, or whether despite different manifestations and articulations, the phenomenology of depression and the essence of the experiences remain universal.

The methodology of the paper follows closely that adopted by Matthew Ratcliffe in his Experiences of Depression (2015), which, as a holistic phenomenological account, covers a wide range of feelings, attitudes, and symptoms in depression. Using data from a qualitative questionnaire, in which those with an experience of depression are asked about various aspects of their experiences of the illness, Ratcliffe offers a holistic account of what it feels like to be depressed. For this research, the same questionnaire as Ratcliffe's was employed in a clinical setting in Iran, in order to conduct a phenomenologically informed cross-cultural study of depression. The questionnaire was translated into Farsi and distributed among patients diagnosed with depression at a University Clinic in Shiraz, ${ }^{1}$ in the south of the country. To probe features of the Iranian experience that prima facie seemed significant, a number of additional questions were also added to the original questionnaire (See Appendix). With 43 participants, the responses were then returned for examination and analysis. The numbered quotations presented in this paper are all from the responses to the questionnaire as conducted in Iran.

A point of cultural difference should be noted at the outset, with regards to the research method employed here. Questionnaires and qualitative studies, especially those that are completed in the absence of a researcher, are less commonplace in Iran than in the UK. A lack of familiarity with the medium may have led to respondents giving rather short answers. Compared to the responses from the UK, for example, the level of detail provided by Iranian patients is much lower, leaving many questions open to speculation and interpretation. However, this methodology has at least established the various themes that are talked about in the context of experiences of depression in Iran, and particular ways of articulating these. In this paper, some of these distinctive features will in turn be accounted for through specific cultural systems of belief and thought.

Noting death-consciousness as a cultural difference that influences experiences of depression in Iran, this paper is organised in two parts. In the first part the case is made for the existence of such a culture in Iran, one which is traceable through the religious teachings and centuries-old works of literature, both central to the ethos of Iranian culture. This death-conscious culture, I argue, has heightened due to experiences of war which remain a strong force in the way Iranians view themselves and their experiences in the world. Having argued for the presence of this culture, the second part of the paper examines the ways in which this cultural preoccupation with death shapes and influences experiences of depression among Iranian patients. I argue that, together with cultural values and conceptions of life, deathconsciousness gives rise to distinctive features in the way depression is experienced among Iranian patients.

Inevitably, the experience of any sort of illness, understood as a bridge between life and death, will be affected by attitudes towards, and preoccupations with death,

\footnotetext{
1 The criteria used for diagnosis of psychiatric disorders in Iran is DSM-IV. Most of the respondents to the questionnaire were formally diagnosed with depression using this criteria. Out of 43 respondents, 38 had received formal diagnosis of depression, 8 were diagnosed with other mental disorders as well as depression, and 5 had not received any formal diagnosis.
} 
which sometimes take the form of what Schopenhauer calls 'denial of life'. Furthermore, the existential feelings brought about in depression (Ratcliffe 2015), which influence one's apprehensions of oneself, one's experiences, and one's world, serve to highlight and amplify thoughts of, and attitudes towards death, which would in turn influence the way one experiences depression and responds to it. As such, certain symptoms and manifestations of depression among Iranian patients can be analysed and accounted for through the examination of the death-conscious culture of Iran. Such an analysis, in addition to accounting for the phenomenological significance of these experiences, also explains the way in which these experiences vary due to cultural differences. Once the central role of death and awareness of it is established, there can be an argument regarding the ways in which this notion influences experiences of depression and responses to it.

\section{Background and Context of Research}

Before proceeding to the main arguments of the paper, it is important to situate this work among the research previously done on Iranian culture, and depression, in particular. The present paper follows on from the previous research which has examined the variations in manifestations of, and encounters with depression in different cultures. Most notable of such works is the seminal collection, Culture and Depression (Kleinman and Good 1985), which brought the importance of culture, as an organising force for frames of thought and interpretation as well as social norms and traditions, to the forefront of research on depression.

In the context of cross-cultural studies of depression specifically focused on Iran, the works of Byron Good and Mary-Jo DelVecchio Good are particularly notable. In their work with Robert Moradi, included in the aforementioned collection, they emphasise the role of dysphoric affect in the Iranian experiences of depression and anxiety (Good, Good, Moradi 1985). Arguing that dysphoric affect is a valued feeling in Iranian culture, they offer a meaning-centred approach to understanding expressions of distress in the Iranian setting. Similarly, Byron Good's work on the semantics of illness in Iran, analyses the syndrome of 'heart distress' in Iran in terms of the semantic network which enables Iranians to express social distress in medical terms (Good 1976).

More recently, Orkideh Behrouzan has offered an account of depression in Iran that appeals to generational memories and collective experiences of the 1980s generation (Behrouzan 2016). In this work the emphasis again is on the use of medical nomenclature to frame and express shared collective experiences; the medicalisation of discourse of trauma. This recent addition to the otherwise sparse body of literature on depression in Iran, offers a unique insight into a specific use of medical language in describing and expressing distress and trauma among a specific generation in Iran.

The aim of the present paper is more general than that of Behrouzan's, and therefore, similar to the works by Good and Good (based on their field work in Iran between 1972 and 1976), insofar as it does not focus on a particular sub-population within Iran. However, there are important differences between this study and that of Good and Good. First is the concern with the phenomenology of depression in the present work. Whilst Good and Good argue for the importance of a meaning-centred 
approach to the study of depression as situated within a cultural context, the present work aims to examine the particular ways in which cultural norms and frames of thought shape the way depression is experienced and articulated. Second, it should be noted that the sociocultural make up of Iran has changed considerably since the studies conducted by Good and Good, due to the shift in the value system of Iran following the Islamic revolution, the rapid modernisation of the country, as well as a population boom which has seen the population of Iran more than double in that time span. Given such changes, there are aspects of the findings of the research conducted by Good and Good which I would argue ought to be revisited. Elsewhere I offer updated analyses of both the understanding of sadness in Iranian culture, as well as of somatic syndromes emphasised by Good and Good in their research (Mirdamadi, forthcoming).

Some aspects of the cultural preoccupation with death as I describe in the paper, resemble elements found in other cultures and thus may not come across as uniquely Iranian. There are clearly commonalities between Iranian culture and others which might arise due to the geographic proximity (e.g. the Mediterranean nations), and/or shared history (e.g. Afghanistan). ${ }^{2}$ In this paper, however, I focus solely on Iran. I actively avoid drawing parallels with other cultures, or grouping cultural elements together, in order to avoid overlooking nuances that are unique to one culture. As such, my emphasis here is with the uniquely Iranian cultural elements which can be invoked in accounting for variations in experiences of depression. For instance the continuing influence of the Iran-Iraq war on the culture, Shi'ism in its uniquely Iranian form, and modern Iranian literature, in addition to the older Persian literature whose influence, rather than limited to Iran, extends to other Farsispeaking countries, and the Muslim world more broadly.

\section{The Death-Conscious Culture of Iran}

The Iranian preoccupation with death can be seen in various domains of culture and social life, with a long history and tradition that has arguably resulted in such concerns being engrained in the cultural framework for thought and practice. Indeed, the preoccupation with death, both as a physical end to the worldly life, as well as a gateway to heaven and hell, can be seen and traced in various cultural domains, such as the religious practices, the works of literature and poetry, as well as in social domains. ${ }^{3}$ The collective experiences of war and the devastating effects it has had on a large part of the population, has also shaped, in large part, the existence of the culture of death-consciousness as presently seen in Iran. Although

\footnotetext{
${ }^{2}$ Examples where such commonalities are seen include Gaines and Farmer (1986), Davies (1999), and Eggerman and Panter-Brick (2010).

3 Mohammad San'ati, a psychoanalyst and literary critic in Iran, claims that a broad range of behaviours seen among Iranians can be attributed to, and explained by, the observation of the culture as a deathconscious one (alternatively termed 'death culture') (San'ati 2004). This account is mostly brought out in terms of works of literature, and aimed at explaining the everyday and routine behaviours of Iranians. Whilst borrowing the notion, I aim to give a more general understanding of the culture, and use it to account, specifically, for experiences of depression in Iran.
} 
this collective experience itself has shaped a large part of the Iranian consciousness today, as I will show, its continuing power in framing cultural ways of thought and interpretation is in part due to the pre-existing cultural and religious landscape in Iran. In examining this death-conscious culture of Iran, the role of the Islamic Revolution and the establishment that resulted from it ought to be considered. Being ideological in nature, it has had the power of directing this culture in a way that is pervasive in all aspects of one's being. This is seen clearly in the discourse of war, as well as the way religious elements of death-consciousness are taught in schools and talked about in mass media on a daily basis. Although the focus in this paper is on historical and cultural roots of death-consciousness in Iran, the undeniable role of the state should be borne in mind, as a powerful force in shaping the dominant culture and values in Iran today. It is, of course, important to note the variety in the approaches to understanding and encountering death in the Iranian culture. My argument, rather than implying that this form of death-consciousness is the only way of thinking about death in the Iranian culture, should be taken as highlighting that it is a dominant way of doing so. This dominance is due in part, as noted above, to the ideological nature of the state, which tends to highlight a particular narrative, and in part due to the recent history of Iran, which has further strengthened this narrative. As such, whilst this culture, due to its dominance and presence in the daily lives of Iranians, has a large influence on the common ways of thinking about death, it is by no means the sole narrative. ${ }^{4}$

\section{Iran-Iraq War}

In the 1980s, Iran went through one of the longest wars in the 20th century with Iraq. The war started in September 1980, only a year after the Islamic Revolution which resulted in regime change in Iran, and went on for 8 years until it ended in July 1988 following the United Nations Resolution for a ceasefire. The devastation of the war reached far beyond the border with Iraq and affected every single area of the country, following 'war of the cities', a bombing campaign by the Iraqi forces which targeted civilian areas to "help to break the enemy's will" (McNaugher 1990:8). Such bombing campaigns were in addition to the use of chemical weapons on the Iranian population which killed many and caused lifelong injuries to many more. Official statistics by the Iranian Military, which were not published until 2015 , estimate that a total of five million Iranians were directly involved in the war-including military, voluntary, and logistical forces. By the end of the war, 190 thousand were killed, 16 thousand of these during the bombing of residential areas, and the rest in the frontlines. Among the dead were 33 thousand school students and over 3.5 thousand university students. The number of those who suffered lifelong injuries, chemical or otherwise, stood at 672 thousand, while there were 42 thousand who were taken hostage and returned to Iran following the end of the war

\footnotetext{
${ }^{4}$ For instance, much of the mystic poetry and literature is seen as hopeful in the way it celebrates life. Yet this aspect can be overshadowed by the life-denying elements of these works due to, for example, the state-imposed censorship, preventing these elements to be brought out in the open as much as other aspects.
} 
(TarikhIrani 2014). About 5 million of the population from the worst hit areas, were displaced and sought sanctuary in the central parts of the country.

Following the Islamic revolution in 1979, the newly established government started promoting larger family sizes, in a reversal of the previous government's policy. With the start of the war, these promotions carried stronger emphasis, since a larger population was seen as an advantage in the war (Karamouzian, Sharifi, Haghdoost 2014:231). The population boom resulting from such policies was such that a large part of the present population of Iran, was either born, or had a large portion of their childhood spent during the war. The traumatic experiences of war, and the memories which remain in the collective consciousness of this generation, such as the sounds of the sirens warning of airstrikes and urging citizens to take shelter in underground shelters, remains part of the generational sense of identity of the young population of Iran (e.g. Behrouzan 2016). As such, the experiences of war, rather than limited to those who fought at the frontlines, affected everyone in one way or another.

Such experiences, furthermore, have not been limited to those who lived through the war. Government policies act not only to keep the memories of war alive, but also to sanctify the horrors of the war. For instance, the tales of those killed in the war were made into compulsory school curricula-most famously the story of Hossein Fahmideh, a 13-year-old boy who was killed at the beginning of the war. Giant murals of those killed in the war were put up on streets and highways (and remain until the present day), and roads and alleys everywhere are named after those killed. The dominant discourse around the war, continues to sanctify the horrors of war: it is not a 'war', but 'The Holy Defence', and those killed are not 'casualties' but 'martyrs'. Various national ceremonies aim at keeping the stories and memories of the lives lost alive. In addition to such efforts, the traumatic experiences of the war continue to haunt, not only those families whose children's remains were never found and for whom loss remains a timeless pain, but the whole nation. People continue to lose their lives in minefields which are yet to be fully cleared (BBC Persian 2017). In 2015, the bodies of 175 divers who had been taken captive in 1986 were found, after they were buried alive over 30 years earlier, and as recently as September 2017, the remains of a 13-year-old boy, killed in the war was returned to Iran to be buried after 34 years.

The memories of war and its traumatic experiences, centred around death and lost lives, far from representing an event in the distant past, are part of the daily routines and preoccupations of Iranians, and continue to shape people's lives, thoughts and feelings. Not only do the memories continue to haunt those who experienced the war, but even for those born after the end of the war, the wounds and the aftereffects of it remain a tangible force. One of such effects, I would argue, is the relationship Iranians have with death, as something always near and always looming. Arguably, with the immense shared sense of loss, and with daily reminders of death, this relationship with death goes a step further than the existential feeling every human being, regardless of culture and society, is preoccupied with in their lives. This constant awareness and consciousness of death, as seen in Iranian society today, however, despite being amplified by the effects of war and the devastation it inevitably brings and which lasts for years after it ends, is also traceable to other 
elements of Iranian culture with a much longer history. It is the combination of historical context and current sense of life and experiences that gives rise to the culture of death-consciousness in Iran.

\section{Shi'ite Teachings}

It is widely thought that in religious societies, fear and anxiety towards death is considerably lower than non-religious societies (e.g. Soenke, Landau, Greenberg 2013; Koenig 2009), due to the comfort gained through faith in the afterlife and the existence of a realm beyond the physical one inhabited during one's life. However, there is a tension that should be noted in discussing the link between religious teachings and beliefs, and the notion of death. Despite the reassurance to believers that death, rather than understood as an endpoint, should be seen a gateway to another, more permanent realm closer to God, believers are simultaneously invited to be aware and fearful of death and possible punishments in the afterlife in every instance of their lives. This dichotomous portrayal of the notion of death and how one ought to relate to it, could arguably lead to an ambivalence that could further enflame the anxieties people feel towards death. The teachings and practices of Shi'ism, for example, can serve to show this tension.

One of the most important practices of Shi'ism in Iran, is the annual commemoration of the battle of Karbala, in which the third Imam of Shi'ite Muslims, Hossein, was killed. The ritual, centred around the death of Imam Hossein and his followers, involves performances depicting the killing of important figures, and the public mourning of the lost lives. Although this ceremony carries significant meaning regarding important notions such as justice and bravery (see Fischer 1980), the centrality of death in the rituals is noteworthy. The annual reliving of the battle that took place over a thousand years ago, and keeping the memory of the death of religious figures is in part based in the Shi'ite teachings which encourage remembrance of death in every instance of life. In carrying out such annual rituals, Iranians are, in addition to keeping the memory of important religious figures alive, following one of the most central teachings of Shi'ism.

One of the most important texts in the teachings of Shi'ism is Nahj al-Balagha, the collection of letters and sermons attributed to Hazrat-i Ali, the first Imam for Shi' a Muslims. Hazrat-i Ali embodies, for Iranians, the ideal character, with all virtues attributed to him (Bateson et al. 1977), and therefore, his collection of teachings remains one of the most adhered to text for Shi'ite Iranians. The notion of death and the individual's relation to it is one of the topics covered extensively in these teachings, so much so that this particular text is considered to put forward one of the most important narratives of death in Shi'ite thought (Nejati Hosseini 2013). These teachings cover a wide range of issues including the fear of death, the inescapability of death, the constant remembering and the impossibility of forgetting death and death as the end of the (physical) world.

One of the most important points of emphasis in this text, is the necessity of 'death-consciousness' (marg-āgāhi). It is argued that this way of being offers a way for the believer to "know themselves, and in turn, find a way of understanding the meaning of life" (Taheri Sarteshnizi and Moosavi 2012:177-my translation). On 
this point, the life of a person who has forgotten death, and in turn has forgotten the afterlife, is likened to the state of the one walking in complete darkness, lost and led astray by the darkness (Letter No. 31). In such an instance, one is reminded that "with death, the darkness is removed and the truths [of the world] are illuminated" (Taheri Sarteshnizi and Moosavi 2012:180—my translation). Thus, it is implied that remembering death at every living moment, would in fact give one a better understanding of the world and how one ought to live in it. This kind of encouragement is further justified through ethical obligations and the encouragement to be good. Since in the Islamic teachings, one's life is merely a preparation for the afterlife, the belief in the immanency of death serves as a reminder for believers that they need to do good, as there might not be time to make up for any bad or unethical deeds they commit. As such, there are short bold reminders of the immanency of death in this text: "anticipate your death by good actions ... and prepare yourselves for death, since it is hovering over you" (Sermon No. 64).

In illuminating the true meaning of life, consciousness of death also serves as a reminder of the illusory value we tend to attach to material things that bring us joy, or otherwise present themselves as valuable. This again can be understood through the portrayal of this world and our lives in it. As the Islamic teachings hold, this world is merely a passageway to the afterlife, and is a means of preparation for the good life one could lead in the more permanent afterlife. Meanwhile, this world is portrayed as deceptive, with various material things or events that could distract one from the main aim, namely preparation for the afterlife. As such, remembering death, is in a sense a reminder of the life awaiting the believer and can serve as a preventive force against the distractions of the material world.

In this latter justification of death consciousness, another element closely linked with it is manifest, namely the denial of earthly pleasures and joyous acts and things, since these are construed as distractions from the real values and the real meaning of life. This element of denial of life, in the face of awareness of death is in itself noteworthy in distinguishing the culture of death-consciousness in Iran from the existential preoccupation with death seen in different cultures. The religious teachings of Shi' ism (and especially Islamic mysticism which dominate some of the most important literary works of Iran), are filled with such claims regarding the value we tend to mistakenly attach to the material things.

One can find various other examples from different Shi'ite texts that encourage consciousness of death. However, it is important to note that these teachings, have found their way into the literary ethos of the Iranian culture, and despite having their root in religious teachings, are not limited to this domain.

\section{Literature}

Persian literature has been, for centuries, a mirror of the Iranian culture and concerns of the society. ${ }^{5}$ Notably, poetry plays a particularly central role in Iranian

\footnotetext{
${ }^{5}$ It should be noted that the official status of Persian language in Iran plays a significant role in the influential power of Persian literature, arguably at the expense of a number of other languages prevalent around the country.
} 
culture. "For Iranians, poetry precedes literacy; it is carried 'in the chest', an expression indicating that Iranians' poetic heritage lives on from one generation to the next, in hearts and in memory, shaping part of the cultural aesthetics of the literate and illiterate alike" (Behrouzan 2016:13). Despite the changes to the language itself over the years, pieces from literary works, and especially poetry remain a strong medium through which Iranians express their emotions and everyday concerns and preoccupations. As a dominant form of art in Iranian culture, an examination of poetry and literature offers an insight into the social and political changes in the Iranian society, especially in the modern era. The preoccupation with death, has been, and remains, one of the central elements in Iranian literature.

The concern with death and attitudes towards it as portrayed in literature, can be broadly divided into the more religiously oriented works and those more concerned with the socio-political environment of the country. Given that both strands remain significant in the Iranian culture today, I will give a brief outline of the points of emphasis in these domains.

Most notable in the religiously oriented pieces of work, are those by poets from the mystic and Sufi traditions, such as Rumi and Attar. The works inspired by the spiritual and religious practices, often reflect the denial of earthly pleasures and attachment to them, as seen in the Shi'ite teachings, while at the same time highlighting the inevitability of death and the important role it plays (or should play) in the way one conducts oneself. Certain pieces of poetry, however, go even further than the religious teachings, and as well as construing earthly pleasures as worthless in the face of death, view all earthly suffering as portions of death (Rumi 1881 [c.1260]). Such a portrayal represents one of the important cultural conceptions of life and suffering in Iranian culture: just as death is inevitable, so is suffering in this world. And, furthermore, if one is wise, one ought to embrace this suffering, since denying it would amount to denial of death as a necessary element of life, and thus ultimately living a lie. In contrast, the more one embraces the suffering in this world, whatever form it takes, an easier and 'sweeter' death and afterlife will be rewarded (Attar 1984 [1177])

The role of the Islamic culture in shaping the dominant frames of thought reflected in the literary works of 12 th-13th century is evident, and figures such as Rumi and Attar remain central cultural figures in Iran today. However, in the more contemporary setting, the focus has shifted from the religious, to the socio-political concerns. The emphasis placed on death is also framed in terms of these concerns, with reference specifically to dissatisfaction and even hatred of life itself. In this sense death is portrayed as the only escape from the absurdity and suffering of life, and the tension between viewing death as a desirable state and the natural fear of death is clearly seen in various pieces of work.

Sadegh Hedayat, as one of the most influential figures in contemporary Iranian literature and thought, distinctively frames death-consciousness in terms of dissatisfaction of life. In Hedayat's writings one clearly sees this tension between hating life and being fearful of death, suffering in life and awaiting death, whilst at the same time being critical of the way death and death consciousness have been encouraged in the culture. There is love for life but longing for death, both playing a part in their writings. This is seen in the famous opening of The Blind Owl where he 
writes: "there are certain sores in life that, like a canker, gnaw at the soul in solitude and diminish it" (Hedayat 1974:1). It is this kind of sores, these sufferings in life which, for Hedayat, act as a drive towards voluntary death, despite a deep fear of death. Sufferings which make life itself seem unworthy of living and death seem the ultimate saviour.

The works by Hedayat, and others influenced by him, ${ }^{6}$ mark a move away from the religious understandings of one's relationship with death. This move is one from viewing the joys of life as worthless in the face of death, to life itself losing its meaning and becoming absurd when faced with the inevitability of death. 'The sores that gnaw at the soul', for Hedayat represent an unresolvable dichotomy; the social and cultural constraints that limit one "because he cannot go further than the line drawn for him" (Hedayat 1948:13 - my translation), but also "a closed condemnation that follows [him], that his encounter is only with absurdity and the absurdity is the shallow and mortal life, thus the acceptance of the final nothingness" (San'ati 2015:7-my translation). This dichotomy, being condemned to be face to face with the inevitable nothingness of life whilst being unable to escape from it, creates an existential anxiety that is manifest in Hedayat's writings, and results in a turn to death. As San' ati puts it, "if this existential anxiety dazzled Kafka in an animal depersonalisation, caused Sartre nausea and led Camus into alienation and estrangement, for a mentality like Hedayat's, it brought suffocation and death" (Ibid.-my translation).

As can be seen from the exposition above, the emphasis on death and deathconsciousness is one of the central elements found in Iranian culture. This emphasis goes back to the religious teachings and has been one of key themes explored in literary works. This pre-existing culture, has been further strengthened through the experience of the war which continues to influence the collective consciousness of the population and the dominant discourse. This culture of death-consciousness is manifested in the experiences of depression among Iranian patients and can be used to illuminate some of the phenomenological differences between experiences of depression in Iran and the UK.

\section{Death-Conscious Culture and Depression}

Having established the existence of a death-conscious culture in Iran, and the place it has in cultural conceptualisations and the dominant discourse in society, in this section I examine the effects of this culture on the manifestations of depression among Iranian patients. I will first look at attitudes towards suicide and suicidal thoughts and the kind of responses people have to these. I will then turn to depressive symptoms, such as feelings of hopelessness and the way patients' articulations and experiences of these symptoms is informed by this pre-existing culture. I will argue that certain differences in experience between Iran and the UK, such as the presence of a strong feeling of absurdity among Iranian patients, can be accounted for through the difference in relations with death.

\footnotetext{
${ }^{6}$ Most notable of these is Mehdi Akhavan-Sales who, in his poetry makes clear the tension between loving life and desiring death, especially in the face of socio-political dissatisfaction.
} 


\section{Death-Consciousness and Suicide}

In Iran, as elsewhere, depressed patients are preoccupied with thoughts of death and suicide:

\#4 - The world seems arbitrary (alaki) and like a game and I wish my life would end sooner.

\#6 - I suddenly get free ( $r a h \bar{a})$ of all mental and emotional bounds (ta'alogh)

and I only want not to be. Although I always prefer not being, to being, but in episodes of depression I think about it more and get closer to it.

\#7 - [I] wish I would die. How long do I have to suffer here. To what end

(äkharesh ke chi)? All levels of life are pointless and it ends in death!

$\# 10$ - [In depression] the feeling of death becomes stronger in me.

$\# 15$ - I think depression is a lack of desire to continue life.

\#19 - I feel I have had enough of life and want to end my life and die.

It should be noted that there were no questions specifically on suicide in the questionnaire, and the above quotes are responses to other questions. Suicide is considered to be a cardinal sin in Islam, and in various religious texts it is seen as grounds for a long or even an eternal punishment. For example, in the Quran, it is said “...Nor kill (or destroy) yourselves: for God hath been to you most Merciful! If any do that in rancour or injustice, soon shall we cast them into the fire; and easy it is for God" (The Quran 4.29-4.30). In a sermon attributed to Imam Sadiq, the sixth Imam of Shi'ite Muslims, it is also emphasised that whoever knowingly kills himself, will forever burn in the fires of hell (Al-Koleini 1990). The condemnation of suicide in religious teachings has multiple consequences. In Iran, with a religious state governing religious people, although suicide is not an illegal act, there is a noticeable lack of research, quantitative and qualitative, on suicide. To protect its image as an Islamic country no reliable statistics on rates of suicide are collected, since acknowledgement of the phenomenon would imply the existence of people disregarding religious rules prohibiting suicide.

In the absence of such statistics and research, it is difficult to say in general terms, what attitude Iranians take towards suicide. However, scattered first-person and eye witness accounts suggest that at least the rates of suicide attempts, regardless of whether they are successful or not, are high. In a newspaper article in October 2016, for example, in which the reporter spends the night in an emergency room for poisoning at a hospital in central Tehran, it is reported that in the 12 hours between $8 \mathrm{pm}$ and 8 am, 33 people were brought into the emergency room, 26 of whom had attempted suicide by taking pills and/or poison (Samgis 2016). All of those admitted to the hospital for attempted suicide were aged 16-40 and most of them had a history of psychiatric illness. The interviews with the staff at the emergency room suggests that such a rate of suicide attempts was common in that hospital.

\footnotetext{
7 The point regarding suicide appears alongside stealing and consuming another's wealth 'unjustly'. The 'rancour or injustice' referred to here, can be in reference to the earlier line. Equally it could refer to suicide: since God as the creator of all individuals knows best when to start and end a life, taking the matters in one's own hands is seen as an aggressive act of injustice to the pre-determined order of the world.
} 
One should be wary of generalising from this situation to all of Iran, however, due to the population of Tehran which is matched by no other city, as well as the high level of social problems and anxiety resulting from it, which sets life in Tehran apart from other cities and regions in Iran. ${ }^{8}$ Despite such differences, and based on the available evidence, and following the global rates of suicide, ${ }^{9}$ it can safely be supposed that the number of suicide attempts is higher among the younger population in Iran. One factor plausibly at play has to do with the generational difference in religious beliefs, which leads to different attitudes and interpretations of the death-conscious culture of Iran.

Notably, the older generation tend to have stronger religious beliefs and adhere to a more literal reading of religious teachings, as compared to the younger generation. Those adhering to a more literal reading of religious teachings are more likely to avoid committing suicide. Instead, as a psychiatrist in Iran has told me, patients suffering from depression in Iran, due to their religious beliefs which prohibit taking one's own life, often resort to what is termed 'passive suicide' [in English]. This consists in praying for God to end and take one's life, rather than acting oneself and taking the matter in one's own hands. In other words, although almost all patients diagnosed with depression are occupied with suicidal thoughts, given their fear of God, and following the Islamic teachings, which see suicide as one of the cardinal sins, the majority would rather not act upon these thoughts themselves (Moghimi 2017, personal correspondence). Asking God to take their lives would mean they have fulfilled their wish to die to an extent by articulating their thoughts and desires to an all-powerful Being, whilst at the same time circumventing committing a punishable sin and going against their faith and beliefs. This can be seen as a direct consequence of death-consciousness, as encouraged by the religious teachings, which could also be seen as consciousness of the afterlife and judgement day. Those who take these teachings to heart, would certainly be wary of the consequences of their actions and the effect it would have for their life after death: taking one's life would certainly threaten the reward they expect and guarantee a heavy punishment.

On the other hand, thoughts and attitudes towards suicide among those for whom the faith and belief in various religious teachings are less strong, tend to be different. Particularly, for those who are persuaded with the kind of frustration with life and its absurdities as portrayed in the 20th century works of literature, deathconsciousness would more easily translate to suicidal thoughts that potentially initiate action. A more individualistic approach to religion, which leaves space for personal interpretations of the religious values and teachings has been increasing and is now fairly common amongst young Iranians (e.g. Alamzadeh and Rastegari 2015; Shojaeizand, Shariati Mazinani, Habibzadeh Khotbeh Sara 2006). Those who take the literal readings of religion to heart would be more prepared to accept as given the teachings of Islam by a religious expert/cleric. This is while those with a

\footnotetext{
${ }^{8}$ Some of these issues include, the often life-threatening air pollution, extremely heavy traffic, timeconsuming bureaucracy, and the high cost of living compared to other cities in the country. All of these issues contribute to high levels of stress, and aggressiveness, often reported in Tehran, which are not seen to the same extent in other cities in the country.

${ }^{9}$ Based on the World Health Organization's findings, suicide is the second leading cause of death among $15-29$ year olds globally.
} 
more interpretive and individualistic attitude to religion are more sceptical and tend to project their own values and personal feelings and experiences on the religious values and teachings. From such a viewpoint, for example, one might accept prima facie that suicide is sinful, and yet argue that individuals are responsible for how their life develops and ends. In the face of immense suffering, therefore, it would not be uncommon to hear reasoning along the lines that 'even God would not want to see me suffer in this way'. An alternative option might be to prioritise other teachings above those concerning suicide, and to hold, for example, that the fact that God is all-forgiving takes precedence over suicide being a cardinal sin.

One important observation that needs to be acknowledged here, is the role of religious beliefs in individuals' wellbeing. It is generally accepted that religious beliefs have a positive role to play in wellbeing; increasing one's happiness and satisfaction of life, as well as hopefulness and optimism (Van Ness and Larson 2002). However, the relationship between religiosity and fear and anxieties in the face of death, is not straightforward (e.g. Thorson and Powell 1988, 1990). As can be seen from various studies done in Iran, "religion acts as a means of protecting and improving the state of acceptance and readiness towards one's own or another's death" (Nejati Hosseini 2013:42 - my translation), whilst at the same time acting as a factor that can increase fear of death. In a 2014 study, which examines the reasons and elements contributing to fear of death, the largest factor was found to be "pain and punishment in the afterlife", with "failure to do religious duties" as a reason highly correlated with belief in religious teachings (Aflakseir 2014:25-26). In other words, whilst everyone taking part in the study identified the afterlife as a main cause of their fear of death, those who hold religious beliefs, see failure to do what is required by their beliefs, arguably another articulation of punishment in the afterlife, as the main reason for their sensed fear of death. As such, the argument presented here, in so far as it is concerned with anxieties arising from awareness of death as seen in religious teachings, rather than consolations received about these anxieties from religion, remains intact.

\section{Death-Consciousness and Depressive Symptoms}

I will argue that certain symptoms and manifestations of depression seen in Iran, including feelings of hopelessness and absurdity, can be closely linked with the death-conscious culture. Additionally, by giving rise to these feelings as seen in depression, death-consciousness can also have an effect on certain help-seeking behaviours in patients with depression, as well as other mental illnesses (e.g. San'ati 2004). As such, I argue that the existence of these feelings among Iranian patients, and the phenomenological differences between these feelings as felt in Iran and the UK, could be attributed to, and interpreted in terms of this death-conscious culture.

Some degree of hopelessness seems to be a universal part of the experience of depression. Based on the results from the questionnaire, I suggest that the emphasis on loss of hope is higher among Iranian patients than those in the UK. Hopelessness is central to the Iranian experience of depression, so much so that often patients define depression itself in terms of hopelessness. 
\#3 - I think depression has a strong correlation with hope, losing hope/ becoming hopeless for whatever reason in my opinion is depression.

\#14 - In my opinion depression is the feeling of hopelessness and despair, which causes one to become incapable of doing the normal daily tasks.

Ratcliffe argues that the sense of hopelessness in depression is rooted in the existential change one goes through in depression, since the existential loss of hope in depression is fundamentally different, and phenomenologically stronger than the intentional hopelessness one might feel in everyday situations (Ratcliffe 2015). As an intentional state, intentional hope is about something in the world; I hope that event $x$ happens. Similarly, losing hope for event $x$ can be construed as no longer having the intentional state of hope, for a certain event $\mathrm{x}$. What defines existential loss of hope, Ratcliffe argues, is the transformation of one's space of possibilities into one of impossibility, where hoping for a state of affairs to come to be becomes essentially irrational, since the very possibility of the desirable state of affairs is under question. While I agree with this characterisation of hopelessness in depression, I would argue that one needs to say more about how this process of the transformation of the space of possibilities into one of impossibility is brought about and how individuals respond to this transformation. In the case of Iranian patients, I will argue this process is intimately linked with the Iranian conceptualisations of life and depression, whilst the responses to this transformation are connected with thoughts and practices of death-consciousness.

$\# 14$ - I saw the world as uncertain [mobham], and full of hopelessness and despair (ya'as).

\#25 - [When depressed] the world has no meaning for me and I'm not hopeful about life.

\#28 - My depression has caused me to be dispirited about life and has caused me to continue life with hopelessness.

\#15 - Depression means feebleness (bi-hoselegi), restlessness, hopelessness.

There are two elements at play here, understanding both of which is essential in understanding the feelings of hopelessness in depressed patients in Iran and the emphasis placed on this feeling as a central symptom of depression; namely, the cultural conceptualisations of depression and the Iranian conceptions of life itself.

The common conceptions of depression in Iran often attribute the cause of depression to an outside source, out of the control of the individual. This is such that, in almost all the instances of the questionnaire responses, patients are able to identify an external event as responsible for them becoming depressed, such as difficult financial situation, unemployment, or family problems. ${ }^{10}$ As such, there is often an element of dissatisfaction with the world in which one dwells and a sense of one being a victim of these outside influences. In such a conception, one's efforts in taking control of one's life and protecting oneself against the outside influences are felt to have been in vain - and it is through the realisation of this effort in vain that depression comes about. Depression, from its conception to its manifestations

\footnotetext{
${ }^{10}$ The majority $(74 \%)$ of all the respondents specify what they regard as the cause of their depression. Within this majority, about $72 \%$ identify the cause to be external to them and out of their control.
} 
as seen in Iran, seems to be the embodiment of the struggles of one against the world, and a state which is, to a certain extent, reasonable given these struggles.

This latter point is closely connected with the Iranian conceptions of life itself. I argue in detail elsewhere that in Iranian culture life is conceptualised as fundamentally a fight, a struggle to strike a balance between the forces of Good and Evil (Mirdamadi, forthcoming). The theme of the fight between Good and Evil are found extensively in Persian mythology before Islam, as well as in Islamic religious texts. ${ }^{11}$

The feelings of dissatisfaction and the sense of being a victim in the world that are seen in depression, can be thought of as the expression of the inherently unfair fight one is made to endure. In this sense, depression is thought of as the logical ending point, once one realises the nature of this unfair fight. Once one is fallen into depression, and due to the existential change one goes through in depression, which transforms one's perception of oneself and of one's world, the sense of helplessness becomes overwhelming; in such a situation any hope for change and a move forward is lost. In the Iranian conceptualisation, good people should expect to endure pain and suffering as part and parcel of the struggle against Evil. Usually, however, such suffering is accompanied by hope for a better future, which fuels the ongoing fight forward. In depression, this hope for a better future is lost. The existential hopelessness in depression, then, brings into question the very meaning of life as a fight to be fought, and is therefore the hopelessness of even envisioning a change, and conceiving of an improvement in one's life-no hope is left for even fantasising about a different world. This, I believe, is the impossibility people with depression in Iran are faced with, one which, in altering the individual's perceptions, brings into question the meaning of life and the motivation to strive forwards.

I would argue that this explains the way in which one's space of possibilities is transformed into impossibility as a result of the existential change one goes through in depression. Once understood, this process can also illuminate the heavy emphasis placed on feelings of hopelessness as the defining symptom of depression. It follows from the arguments above, that the rootedness of this feeling in the Iranian culture and conceptions gives this feeling the importance and centrality that is expressed by those suffering from depression.

The culture of death-consciousness already prevalent in Iran influences the feelings of hopelessness in Iranian patients (and I suggest this leads to differences between the feelings of hopelessness in Iranian patients and those in the UK). Specifically of importance here are the accounts of life and death as presented in the literature of 20th century Iran. As argued previously, in such works of literature, the message conveyed is one in which dissatisfaction with one's life, and a sense of having lost in the fight for a good life, forces one to come face to face with death as the ultimate end. In this sense, death becomes the only conceivable change, and thus the only goal one is able to hang onto. Death in such a scenario would be the only

\footnotetext{
11 The notions of Good and Evil can be seen in ancient Indo-Iranian mythologies, Zoroastrian teachings (notably the Gathas), and in various Islamic texts. The topic has been debated extensively in Iranian Philosophy (e.g. by Avicenna and Mulla Sadra), and is reflected widely in Persian literature (e.g. Rumi's Masnavi and Ferdowsi's Book of Kings).
} 
place one could take shelter from the hopelessness of life: death becomes the only remaining hope. This pre-existing culture which encourages the remembering of death both paves the way for this form of hopelessness, and offers a way of interpreting and understanding, and thus articulating one's feelings of frustration and dissatisfaction. This existential hopelessness, therefore, places more emphasis on death, as the only possibility amidst the impossibilities of life.

To a certain extent hopelessness can be thought of as a universal part of the experience of depression across cultures. However, the death-conscious culture of Iran, and the sense that life should be a meaningful fight against the forces of Evil, shapes the narratives and interpretations of hopelessness in the culture and gives rise to a certain manifestation and articulation of the symptom among Iranian patients. These culturally-specific manifestations and articulations can be seen in the Iranians' complaints of feeling a sense of absurdity in depression.

\#26 - I feel a sense of absurdity, nothing is interesting for me.

\#21 - I feel a sense of absurdity and feel as if nothing is right and everything is a lie.

\#9 - I think the world has no attractions even in the moment. Merely passing time and life without anything else.

\#35 - I feel sadness and sorrow and [a sense of] absurdity.

\#36 - I feel that the world is completely absurd and futile.

\#41 - Depression means feeling absurdity, and life becoming meaningless.

A linguistic point is worth making here regarding the meaning and connotation of the words translated as 'absurdity' in these quotes. The word used by Iranians, poochi (noun), which I have translated as absurdity, is derived from the adjective pooch which itself carries various meanings and heavy connotations. Among the dictionary meanings of pooch are empty, hollow, pointless, futile, nothingness, nonsensical, and lacking in meaning. Given these definitions, then, it can be seen that what Iranians mean in talking about feelings of absurdity or poochi in depression, is an expression of the way they see the world and themselves in it. Furthermore, given these meanings, the link between this expression and those of hopelessness become clear, since they are both rooted in the Iranian conceptualisations of life. The feelings of absurdity in this sense, emphasise the feelings of defeat and meaninglessness of the fight which is life. The perception of meaninglessness is of key importance here. In contrast to patients in the UK, Iranians in describing their experience of depression, rarely talk about feelings of sadness. Plausibly this is because the conceptualisation of life in Iranian culture, views sadness and suffering as essential to the pursuit of Good (cf. Good et al. 1985). In other words, in the fight between Good and Evil, if one is to be on the side of the good, one ought to expect to endure the sadness and suffering that is inevitably involved in this position (Mirdamadi, forthcoming). Complaining about feelings of sadness, therefore, is often interpreted as a mark of a weak character. In the Iranian conception of life, meaningful sadness and suffering is to be expected and should be endured. However, in depression precisely this perception of life and the world as meaningful is lost. It is this meaninglessness that is complained about when patients talk about a sense of absurdity. Whilst sadness is seen as the hallmark 
of depression in the UK, it is the perception of meaninglessness of the world, and feelings of meaningless sadness that are grounds for complaint for Iranian patients.

This sense of meaninglessness can be seen to be, in large part, shaped by the death-conscious culture. The existential hopelessness in depression, and the impossibility faced by the patients, is further exacerbated by the culture. Since it is in the transformation and perception of this impossibility that the inescapability of death is highlighted as the ultimate impossibility. This fundamental transformation of one's space of possibilities, renders any hope for change, or any effort to the effect meaningless, since one can never win the ultimate fight with death. As such, the existential transformation of the world, as a universal element in experiences of depression, through the lens of the death-conscious culture of Iran, creates a sense of absurdity that marks the cultural variation in experiences of depression. It is this sense of absurdity and meaninglessness which, as a pervasive mood, governs the way one sees oneself and the world around one in depression.

Such a perception of the world is also seen in the way individuals articulate their experiences of depression in Iran. This is seen in particular in the metaphors Iranian patients use in describing their sense of the world in depression. Whilst in Iran people commonly use colour metaphors to talk of an existing mood or emotion they feel, in depression they describe the world as colourless and fading in colour.

$\# 10$ - [In depression] life is pointless, colourless, tasteless and unreal.

\#6 - The positive aspects [of life] lose their colour and sometimes even vanish altogether.

\#3 - In the end life is always a little bit interesting, but it can lose its colour.

The image of a colourless world signifies an idle and meaningless state in which no change can be envisioned and thus any attempt at improving one's state or hoping for a better future is seen as futile and absurd. Taken together, the metaphors of colourlessness and the feelings of hopelessness and absurdity, make the argument for the existence of these feelings, as the defining features of depression in Iran, even stronger. Furthermore, these feelings of absurdity as felt in depression can call into question one's previous understandings of oneself and one's life:

\#3 - I am hopeless and at the same time feel absurdity (poochi) with regards to my life in the past, present and the future.

As if in receipt of a higher understanding, the feelings of absurdity and hopelessness, in the face of consciousness of death, force one to think about the way one has led one's life up to this point and all previous conceptions of life and the world. Death is a sublime which makes one realise one's own mortality and insignificance and such feelings further force one to rethink how one has conducted oneself throughout one's life, and it all seems meaningless, empty, and absurd.

Additionally, following the earlier discussions from the religious teachings which encourage the remembering of death as a preventive force against the earthly joys of life, this feeling of absurdity and meaningless of life in depression, can affect the behaviours patients have in response to depression. The disposition of denial of life, brought to the foreground in light of the feelings of absurdity of life, could in some instances dampen the motivation to seek help. The unwillingness of Iranian patients 
to seek help and an effective treatment, presents a challenge for mental-health professionals (e.g. San'ati 2004). Such behaviour can further be explained through the conceptualisation of every suffering as 'a portion of death', and thus as inevitable as death itself. If the suffering in depression is conceptualised in this way, and if, as a result of the feelings brought about by depression, the thought of death and its conceptualisations in the culture is brought to the fore of one's attention, then one might see this suffering as necessary, as something to be embraced, or endured, rather than treated. In instances where these various elements are seen to be at play together, the unwillingness to seek help and treatment can be explained against the backdrop of the cultural conceptualisations of death and death-consciousness.

\section{Conclusions}

In this paper I have argued that Iran has a death-conscious culture. The existence of this culture is manifest through the religious teachings, as well as in many literary works, religiously oriented and otherwise. This culture has been made even stronger following the Iran-Iraq war and the discourse around the war which remains a strong factor in the way Iranians think about and relate to death. Deathconsciousness, as I have used the phrase, encompasses a range of attitudes towards death, centred around the awareness and remembrance of death, whether as a means of remembering the afterlife in case of religious teachings, or as a desired state in the face of dissatisfactions with life in the case of the modern literature. All the while, these attitudes are heavily influential in the way Iranians conceptualise themselves and their lives, and their relation to the world in which they dwell, and are therefore phenomenologically significant. I have examined the effects of this pre-existing culture on the experiences of depression, as seen in Iran. I argue that death-consciousness has a direct effect on certain symptoms of depression as experienced in Iran, and provides a basis for comparison, and a point of divergence between experiences in Iran and the UK. Attitudes and reactions towards suicide and suicidal thoughts, feelings of hopelessness and absurdity, and some helpseeking behaviour, are shown to be largely a consequence of views towards death in the culture.

The exposition presented provides an example where the dominant culture and the cultural ways of thought and interpretation influence the experiences of depression, and shape the manifestations of depression. Experiences find meaning against the backdrop of culture and dominant ways of thought, and the exposition at hand shows the mechanism through which the culture of death-consciousness in Iran plays a role in the experiences of depression.

Acknowledgements I would like to thank Dr. Ebrahim Moghimi (M.D.) and Ms. Sepideh Ghorbani at Shiraz University, who helped in the acquisition of the data.

Funding This study is part of a Doctoral project funded by Lancaster University PPR Department. 


\section{Compliance with Ethical Standards}

Conflict of interest The author declares that she has no conflict of interest.

Ethics Approval All procedures performed in studies involving human participants were in accordance with, and approved by Lancaster University Research Ethics Committee.

Informed Consent Informed consent was obtained from all individual participants included in the study.

Open Access This article is distributed under the terms of the Creative Commons Attribution 4.0 International License (http://creativecommons.org/licenses/by/4.0/), which permits unrestricted use, distribution, and reproduction in any medium, provided you give appropriate credit to the original author(s) and the source, provide a link to the Creative Commons license, and indicate if changes were made.

\section{References}

Aflakseir, Abdolaziz

2014 The Reasons for Fear of Death and Religiosity with Anxiety in Students in Shiraz University (in Farsi). Journal of Psychology (Tabriz University) 9(35):19-32.

Alamzadeh, Maryam, and Samina Rastegari

2015 Youth Religiosity, Ideals and Facts: A Study of the Limits of religious Discourses in the Analysis of Youth Religiosity (in Farsi). Motale'at-e Jame'eshenakhti (Sociological Studies) 21(2):159_ 188.

Al-Koleini, Mohammad ibn-Ya'ghoub

1990 Osoul Al-Kafi (in Arabic). Beirut: Dar-al Ta'aref al-Matbou'at.

Attar, Farid Ud-din

1984 [1177] The Conference of the Birds. 1st. Translated by Afkham Darbandi and Dick Davis. London: Penguin Books Ltd.

Bateson, M.C., J.W. Clinton, J.B.M. Kassarjian, H. Safavi, and M. Soraya

1977 Safā-yi Bātin: A Study of the Interrelations of a Set of Iranian Ideal Character Types. In Psychological Dimensions of Near East Studies. L. Carl Brown, ed., pp. 257-273. Princeton: Darwin Press.

\section{BBC Persian}

2017 Three Mine Clearing Workers killed and Wounded in the West border of Iran (in Farsi). http:// www.bbc.com/persian/iran-41756957, accessed October 30, 2017.

Behrouzan, Orkideh

2016 Prozak Diaries: Psychiatry and Generational Memory in Iran. Stanford: Stanford University Press.

Davies, Jon

1999 Death, Burial and Rebirth in the Religions of Antiquity. London: Routledge.

Eggerman, Mark, and Catherine Panter-Brick

2010 Suffering, Hope, and Entrapment: Resilience and Cultural Values in Afghanistan. Social Science \& Medicine 71(1):71-83.

Fischer, Michael

1980 Iran: From Religious Dispute to Revolution. Cambridge, Massachusetts: Harvard University Press.

Gaines, Atwood D., and Paul E. Farmer

1986 Visible Saints: Social Cynosures and Dysphoria in the Mediterranean Tradition. Culture, Medicine, and Psychiatry 10(4):295-330.

Good, Byron J.

1976 The Heart of What's the Matter The Semantics of Illness in Iran. Culture, Medicine, and Psychiatry 1(1):25-58.

Good, Byron J., Mary-Jo DelVecchio Good, and Robert Moradi

1985 The Interpretation of Iranian Depressive Illness and Dysphoric Affect. In Culture and 
Depression: Studies in the Anthropology and Cross-Cultural Psychiatry of Affect and Disorder. Arthur Kleinman and Byron Good, eds., pp. 369-428. Berkeley: University of California Press. Hedayat, Sadegh

1948 Gurūh-i Mahkūmīn va Payām-i Kafka (The Condemned Group and Kafka’s Message). 1st Edition. Tehran: Amirkabir.

Hedayat, Sadegh

1974 The Blind Owl. 1st Edition. Translated by Iraj Bashiri. Bashiri Working Papers on Central Asia and Iran.

Ibn Abi Talib, Ali n.d. Nahjul Balagha. https://www.al-islam.org/nahjul-balagha-part-1-sermons, accessed October 23, 2017.

Karamouzian, Mohammad, Hamid Sharifi, and Ali Akbar Haghdoost

2014 Iran's Shift in Family Planning Policies: Concerns and Challenges. International Journal of Health Policy and Management 3(5):231-233.

Kleinman, Arthur, and Byron Good

1985 Culture and Depression: Studies in the Anthropology and Cross-cultural Psychiatry of Affect and Disorder. 1st Edition. Berkeley: University of California Press.

Koenig, Harold G.

2009 Research on Religion, Spirituality, and Mental Health: A Review. The Canadian Journal of Psychiatry 54(5):283-291.

McNaugher, Thomas L.

1990 Ballistic Missiles and Chemical Weapons: The Legacy of the Iran-Iraq War. International Security 15(2):5-34.

Mirdamadi, Moujan

Forthcoming. Cultural Variation in Experiences of Depression in Iran and the UK: A Phenomenological Investigation (Unpublished doctoral thesis), Lancaster University, UK.

Nejati Hosseini, Mahmoud

2013 Death and Dying: Social Science Narratives and Religious Knowledge (in Farsi). Islam and Social Sciences 5(10):37-63.

Ratcliffe, Matthew

2015 Experiences of Depression: A Study in Phenomenology. Oxford: Oxford University Press.

Rumi, Jalāl ad-Dīn Muhammad

1881 [c.1260] Masnavi. Translated by James W. Redhouse. London: Trubner \& Co.

Samgis, Banafsheh

2016 Sā't-i Sholūghī-i Marg (The Busy Hour of Death). Etemad Newspaper, 23 October: 8. http:// etemadnewspaper.ir/Default.aspx?NPN_Id=558, accessed 30 October, 2017.

San'ati, Mohammad

2004 Psychotherapy in a Death Conscious East. 20 September. http://www.mohammadsanati.net/1392/ culturepsychoanalysisiran/584, accessed October 23, 2017.

San'ati, Mohammad

2015 Sadegh Hedayat and Fear of Death: Blind Owl, Cultural History \& Myth Killing, A Psychoanalytic Deconstruction. 6th Edition. Tehran: Nashr-e Markaz Publishing Co.

Shojaeizand, Alireza, Sara Shariati Mazinani, and Ramin Habibzadeh Khotbeh Sara

2006 An Analysis of the State of Religion Amongst University Students (in Farsi). National Studies 7(2):55-80.

Soenke, Melissa, Mark J. Landau, and Jeff Greenberg

2013 Sacred Armor: Religion's Role as a Buffer Against the Anxieties of Life and the Fear of Death. In APA Handbook of Psychology, Religion, and Spirituality. I. Kenneth Pargament, ed., pp. 105122. Washington, DC: American Psychological Association.

Taheri Sarteshnizi, Eshaq, and Maryam Sadat Moosavi

2012 Human Awareness of Death and Meaningfulness of Life in Nahj Al-Balagheh (in Farsi). Ensanpajoohi-e Dini (Religious Anthropology) 9(27):177-198.

TarikhIrani

2014 The Real Statistics of the War (in Farsi). 21 9. https://tinyurl.com/y97m6nh3, accessed October $17,2017$.

Thorson, James A., and F.C. Powell

1988 Elements of Death Anxiety and Meanings of Death. Journal of Clinical Psychology 44(5):691701. 
Thorson, James A., and F.C. Powell

1990 Meanings of Death and Intrinsic Religiosity. Journal of Clinical Psychology 46(4):379-391. Van Ness, Peter H., and David B. Larson

2002 Religion, Senescence, and Mental Health: The End of Life Is Not the End of Hope. The American Journal of Geriatric Psychiatry 10(4):386-397. 